\title{
ПОЛЕМИЧЕСКИЙ ДИАЛОГ
}

DOI $10.37386 / 2305-4077-2021-1-174-182$

\author{
И. А. Шаронов ${ }^{1}$ \\ Российский государственный гуманитарный университет \\ ТАКТИКИ ДОМИНИРОВАНИЯ \\ В ПОЛЕМИЧЕСКОМ ДИАЛОГЕ
}

Диалог для решения задачи успешного коммуникативного взаимодействия реализует одновременно информативную и социальную функцию - передачу информации и сохранение хороших отношений между собеседниками. Данные функции проявляются в разных диалогах неравномерно. Статья посвящена полемическим диалогам, в которых задача достичь результата может не учитывать социальную функцию и приводить к конфликтам между собеседниками. Особое внимание уделено нескольким тактикам в полемике, которые реализуются с помощью коммуникативов - стереотипных речевых формул диалога.

Ключевье слова: социальная и информативная функции, фатика, диалог, полемические диалоги, диалогические тактики, коммуникативы.

\section{Igor A. Sharonov \\ Russian state university for the humanities \\ DOMINANCE STRATEGIES IN POLEMICAL DIALOGUES}

To support successful interaction in dialog it is necessary to realize both informative and social functions that are to convey the information and to maintain good relations between interlocutors. The functions work in different dialogs not always in harmony. The article is devoted to polemical dialogues, the target of which may not take into account social function and even lead to conflicts. Particular attention is paid to three polemical tactics realized with the help of communicatives - stereotypical speech formulas of dialogue.

Keywords: social and informative functions, phatic function, dialogue, polemical dialogues, dialogical tactics, communicatives.

\section{1. Введение}

Диалог как форма межличностного взаимодействия выполняет две основные функции - информативную и социальную, которые выступают неразрывно, то в гармонии, то вступая в противоречие друг с другом. Реализация этих функций определяется коммуникативными задачами коммуникантов и проводится с помощью стратегий и тактик, интерес к которым среди исследователей-лингвистов дискурсивного анализа языка в настоящее время весьма активен (см. подробнее [Шпильная, 2017]).

${ }^{1}$ Игорь Алексеевич Шаронов, доктор филологических наук, доцент, заведующий кафедрой русского языка Института филологии и истории РГГУ (Москва). 
Цель диалогов с социальной (фатической) доминантой определяется желанием говорящего поддержать иукрепить хорошие отношения с собеседниками [Malinowski, 1953]. К таким диалогам относят «светскую болтовню» (small talk), речевые жанры знакомства, встречи и прощания, приема гостей и т.д., предполагающие в основном использование определенного набора обменных реплик этикетного характера. Разумеется, и фатические диалоги информативны в смысле передачи определенного содержания. Но эта информация имеет менее существенный характер и не всегда соответствует истинному положению дел. Ответ на этикетный вопрос: Как дела? должен быть лишен содержательной составляющей, описания истинного положения дел у адресата вопроса, в противном случае фатика диалога разрушается.

Доминирование социального над информативным может проявляться также в случаях, когда тема, которую развивает говорящий, оказывается в той или иной степени неприятной для собеседника, может привести к размолвке, ссоре, и инициатор принимает решение как бы «зачеркнуть» свою реплику, сделать шаг назад, чтобы ввести новую тему. Такой прием «зачеркивания» в микродиалоге при опасности ухудшения отношений производится короткими реагирующими речевыми актами, или коммуникативами: ладно, забудем; ладно, забыли; ладно, проехали (подробнее о коммуникативах см.: [Шаронов, 2016]). Приведем несколько примеров, демонстрирующих данную тактику для сохранения бесконфликтного речевого взаимодействия коммуникантов.

- Что же ты не вышел на палубу? Ведь ты хотел видеть японского моториста? Он сразу помрачнел, но ничего не ответил.-Ладно, забудем... Я не затем... Есть одна любопытная задача... (С. В. Диковский. Конеи «Саго-Мару»).

- Тебе что, имя было трудно написать?! - Я вам не Достоевский! Откуда мне знать, что вы сразу все стрелки переведете на королеву? - Ладно, забыли... Оба хороши: и ты и я! (А. Белянин. Свирепый ландграф)

Что вы все ровните себя-то с ним! Этот ваш Андрюша, он-да, добросовестный починяла. А вы, Захар, вы-талантище, вы-редкийхудожник, так и знайте! <...> Он наткнулся на упрямый взгляд Захара и рукой досадливо махнул:-Ладно, забыли. Пусть тот делает всю технику, но я хочу, чтобы именно вы прописали живопись в местах утрат. (Д. Рубина. Белая голубка Кордовы).

- Вот не пойму я, сосед, почему ты все лето в отпуску. Может, по вредности? $<\ldots>$ Я поведал Вячеславу, что я литератор, <..> А чтобы он мне не завидовал, я, как водится, соврал ему, что гнуть слово не легче, чем железо. Вячеслав мне, естественно, не поверил.-Ладно, проехали,-сказал он.-Обходишься без работы, и молодец. Но как ты обходишься без бабы - вот вопрос. (О. Зайончковский. Счастье возможно: роман намего времени).

В диалогах с информативной доминантой сохранение хороших отношений с собеседником может учитываться в меньшей степени. К ним относятся, например:

- диалоги «собственно информативные», которые обычно происходят при передаче никак не связанной с говорящими информации;

- диалоги «обучающие», которые содержат ожидаемые адресатом советы, инструкции, рецепты и т.д., предназначенные для успешного решения тех или иных задач; 
- диалоги «операциональные», которые происходят в ситуациях, требующих безотлагательного выполнения каких-либо действий. Ср., например, коммуникацию людей при опасности опоздать на самолет, при пожаре, аварии и т.д.

В некоторых из таких ситуаций роль фатики может быть доведена до нуля.

Очевидно, что отношения между функциями неравноправные. Социальная функция до некоторой степени - дополнение к основной, информативной функции. Но поскольку экстремальные ситуации в современной жизни, где фатика отсутствует совсем, явление относительно нечастое, фатическая составляющая, то есть вкрапление в речь знаков почтения к собеседнику, учет и демонстрация уважения к его социальному статусу, внимание к мнению, оценкам собеседника относительно объекта обсуждения и т. д. является крайне важным и продуктивным элементом диалогической речи, ее успешной реализации.

\section{2. Основная часть}

Пренебрежение кроли фатики можетпроявляться также в полемических, или «персуазивных» диалогах, целью которых является попытка перестроить сознание собеседника в определенном направлении, убедить его в правильности мнения о чем-либо, необходимости или полезности того или иного действия. В работе «Путь к согласию» [Фишер, Юри, 1987] стратегии ведения персуазивного диалога рассматриваются в терминах переговоров. Для реализации коммуникативной задачи в диалоге авторами статьи выявлены две принципиальные стратегии, одну из которых выбирает говорящий - жесткая и мягкая. Жесткая стратегия строится на волевом противоборстве своей и чужой воли, неуступчивости при выражении своей позиции. Расчет состоит в том, что собеседник выберет мягкую, унисонную линию поведения, уступит, предпочтя важность сохранения мирных отношений. [Фишер, Юри, 1987, с. 174]. Однако в том случае, если расчет не оправдается, начинается полемика, противоборство, используются агрессивные приемы воздействия, в своем крайнем проявлении доходящее до конфликта - ссоры и выяснения отношений.

В диалоге-противоборстве, полемическом споре или даже конфликте для успеха при реализации жесткой стратегии часто используются манипулятивные тактики дискредитации мнения, позиции собеседника, самого собеседника, см. об этом в: [Шаронов, 1999; Шатуновский, 2016; Брагина, Шаронов, 2019; Иссерс, 2021]. Манипулятивные тактики используются для воздействия не только на собеседника, но и на третьих лиц, слушателей и «третейских судей». Перетягивание их на свою сторону - важный фактор победы в полемике.

Рассмотрим некоторые реактивные тактики контрвоздействия при выборе жесткой стратегии в полемических диалогах. Данные тактики используются как ответ говорящего на реплику собеседника для нейтрализациипротивоборствующей силы и переходу к доминированию, убеждению собеседника в правильности своей идеи, своей трактовки чего-либо. Распространенность рассматриваемых тактик обосновывается реализацией их коммуникативами - стереотипными словами-репликами ответного типа. Стереотипизируется этот языковой 
материал тактиками диалогического взаимодействия или языковой материал стереотипизирует тактики - это вопрос о курице и яйце. Главное для нас, что, анализируя типовое употребление коммуникативов в диалоге, мы можем выявлять и описывать конкретные механизмы диалогического взаимодействия.

В качестве материала исследования выбраны художественные диалоги, большая часть которых собрана в Национальном корпусе русского языка. Рассматриваются следующие тактики разной степени вежливости по отношению к собеседнику, цель которых - в ответном акте воздействовать на собеседника, нейтрализовать силу его предположений, утверждений и аргументов:

1.Нарушение условий коммуникации псевдоответом с целью «педагогического» наказания собеседника.

2. Преуменьшение важности сказанного собеседником.

2.1. Шутливо-ироническое обыгрывание важности;

2.2. Прямая оценка реплики как несерьезной.

3. Коммуникативный подвох при нарушении диалогического взаимодействия.

\section{1. Нарушение условий коммуникации псевдоответом с целью «педагогического» наказания собеседника}

Для русского коммуникативного поведения характерно использование псевдовопросов риторического характера, намекающих на коммуникативную ошибку собеседника, задающего вопрос или утверждающего что-либо. На такую «агрессивно-педагогическую» стратегию обратили внимание при анализе речевого взаимодействия продавца и покупателя (см. [Yokoyama, 1990, Николаева, 1990, Земская, 1994, Розина, 2018]). Ср. пример из работы [Николаева, 1990]: Bbl еще работаете? - А вы не видели табличку: «Обед»? Псевдовопросы используются говорящим в ответ на несоответствующий, с его точки зрения, условиям коммуникации речевой акт собеседника. Тактика использования псевдовопроса или риторического вопроса должна привести собеседника к пониманию, что он нарушил негласные правила коммуникации [Кустова, 2011]. Ср. использование стереотипных формул:

- А где Мама? - Откуда мне знать?

= 'Я не знаю, а ты не прав, полагая, что я могу это знать'.

- Он женится на Оле.-Кто сказал тебе такую чепуху?

= 'Это чепуха, а ты наивен, веря в это'.

Н. Г. Брагина рассматривает фразеосхему: Как(ая)ой я тебе X? с цитатным компонентом, вставляемым на месте $X$, эмоционально используемую в ситуациях некорректного, с точки зрения говорящего, обращения к нему. Ср. примеры из статьи [Брагина, 2018]:

- Антоша... <..> - Какой я тебе Антоша? - возмутился я. (А. Приставкин. «Вагончик мой дальний»). = 'Я тебе не Антоша'.

- Дядя Миша, задымить е? - Какой я тебе, к дьяволу, дядя? Племянничек выискался! (Ф. Абрамов. «Дом»). = ‘Я тебе не «дядя»'. 


\section{2. Преуменьшение важности сказанного собеседником}

Задача выбранной тактики - попытаться убедить собеседника, что его утверждение и/или аргументация несерьезны; ему не следует придавать значения и принимать во внимание. Можно выделить две разновидности такой тактики:

2.1. Шутливо-ироническое обыгрывание важности, выражаемое через коммуникативы: Эка невидаль!, Эка / Велика важность!; Большое дело; Подумаешь! Лексическое значение коммуникативов - указание на важность, большое значение, переворачивается в коммуникативе, превращает оценку воспринятого в неважное, несущественное и колет собеседника как наивного человека, серьезно относящегося к пустякам.

Значит, так, я нашла тебе отличного жениха.-Я замужем,- напомнила Лика.Ну и что? - удивилась Вера,- разведешься, эка невидаль. <..> Лика слегка посопротивлялась, но спорить с Карапетовой невозможно. (Д. Дониова. Уха из золотой рыбки).

- Как ты смеешь, невоспитанная девчонка! - сердито крикнул маленький пажик <...>.- Аx, скажите, пожалуйста, какая неженка! Велика важность - ему прическу смяли! - потешалась Тася, бойко поглядывая на остальных детей, как бы ища у них сочувствия (Л. А. Чарская. Приключения Таси);

- Ты мне нужен. У тебя более практический ум. Ты проследишь, чтобы я не растратил деньги - Но у меня разбита физиономия.- Подумаешь! Кого это волнует?! Я привезу тебе солнечные очки. (С. Довлатов. Чемодан).

2.2. Прямая оценка утверждения или аргумента собеседника как несерьезного, не меняющего мнения говорящего. Для реализации данной тактики используются коммуникативы: Чепуха!, Ерунда!, Вздор!, Глупости!, Чушь!, Пустяки!

К твоему сведению, - сказала она надменно,-я совершенно здорова < ..>. «Зато я болен»,-возразил он.-Э, ерунда. Пройдет. (Б. Хазанов. Корсар).

Ведь я же практически высланный, враг народа. - АА, это чепуха! - отмахнулась она.- Ты же понимаешь! Они могут это повернуть в одну минуту!» (В. Аксенов. Новый сладостный стиль).

Я говорил с одним из ее создателей. Он взял меня за плечо, посмотрел мне в глаза и произнес только: «Леонид, это было страшно». <..>-A, -сказал Банин.- Чушь. Это меня не интересует» (А. и Б. Стругаикие, Далекая радуга).

\section{3. Коммуникативный подвох при нарушении диалогического взаимодействия}

Последняя рассматриваемая в статье тактика отражения довода собеседника основывается на более сложном риторическом приеме. Для ее осуществления используются коммуникативы вот-вот и вот именно. В стандартном диалоге такие ответные реплики используются для усиленного подтверждения. Однако если вслед за коммуникативом говорящий повторяет фрагмент или все высказывание собеседника и переинтерпретирует его, он получает возможность 
сильного контрудара, на который неподготовленный собеседник обычно ответить ничего не может. Продемонстрируем функционирование коммуникативов вотвот и вот именно в двух разных значениях - прямом и переносном - на основе их лексикографического описания в нашей рабочей версии словаря коммуникативов.

\section{BOT-BOT}

1. Горячее одобрительное подтверждение мысли, слова собеседника, полностью совпадающими с мнением говорящего, выбранным словом.

- Все помнишь? - Как не помнить! Любили и мы по черемухам да по рябинам лазить, хлебом не корми.-Вот, вот,-обрадовался он,-хлебом не корми! (А. Яшин. Угомаю рябиной).

Использование коммуникатива в таком значении стандартно. Собеседник настраивается на речевой акт одобрительного подтверждения. Однако в полемической коммуникации говорящий может использовать коммуникатив в другом значении.

2. Подтверждение не утверждения собеседника, а негативных мыслей говорящего о собеседнике на основе услышанного.

- Издеваешься, да? - Очень нужно, еше издеваться...-Вот-вот, тебе ничего не нужно! Тебе все равно... (А. Битов. Жень нет дома).

- Безнравственная наука оказывается хуже и опаснее безнравственного невежества... Тут Павел Алексеевич оживился: - Вот-вот, Илья, всегдашняя твоя тендениия, всё в одну кучу валишь. Путаешься в понятиях. Нравственного невежества быть не может. (Л. Улицккая. Казус Кукоцкого).

\section{ВОТ ИМЕННО}

1. Горячее согласие с мнением собеседника, оценки, характеристики кого-/ чего-Л.

Подумаешь, сейчас каждый пишет диссертацию. Да ещё про каких-то жучков.-

Вот именно! - обрадовался Славкин. (Е. Дубровин, Овсяное печенье).

Аналогично предыдущему случаю собеседник, услышав коммуникатив вот именно! настраивается на речевой акт одобрительного подтверждения, и может так же попасть впросак, когда говорящий использует единицу во втором значении.

2. Горячее согласие периферийным компонентом в утверждении собеседника для последующего отражения этого компонента, а не того, что утверждал собеседник.

«У него расписание, у него времени нет!» Мне мое время в конце конциов тоже для чего-то нужно.- Вот именно - оживился Зильберович. Твое время нужно тебе, а его время нужно всем, всему человечеству (В. Войнович. Москва 2042).

- Tbl, з-з-зачем на мой цветок села? - опускаясь на душииу, прожужжала она. - Почему твой? Я его только что сама нашла.- Вот именно - только что. А я вчера... (В. Кологрив. Медовый луг // «Мурзилка», 2002).

В приведенных примерах подчеркнут фокус утверждения собеседника, который говорящий в своем ответе намеренно меняет на периферийный компонент, чтобы нанести контрудар, реагируя на этот компонент, а не на фокус утверждения собеседника. 


\section{3. Заключение}

В статье рассмотрены диалогические стратегии, учитывающие фатическую доминанту, стремление прежде всего сохранить хорошие отношения с собеседником, и не учитывающие ее по тем или иным причинам. Диалоги в силу активной каждодневной речевой деятельности стереотипизируются, приобретают устойчивые языковые формы, выражающие поведенческие тактики. Изучая ответные формулы диалога, или коммуникативы, можно выявлять стереотипные диалогические тактики. В статье были продемонстрированы, с одной стороны, тактика попытки сохранения бесконфликтного взаимодействия при нарушении взаимопонимания, а с другой стороны, тактики в полемических диалогах, направленные на нейтрализацию мнения, утверждения собеседника, не совпадающего с мнением говорящего. Многие из таких тактик пока не получили должного анализа, их описание раскрывает дискурсивные особенности русского диалога.

Исследование диалогического дискурса на основе анализа функционирования в нем коммуникативов помогает выявлять его риторические свойства и «тайные пружины» воздействия. Агрессивные тактики в полемическом диалоге преследуют коммуникативные цели в ущерб социальным. Прежде чем пользоваться ими, необходимо взвесить силу возможного морального ущерба, опасности обидеть и получить ответную агрессию, важности взаимодействия в дальнейшем, потери от которых могут превзойти актуальную выгоду победы в полемическом диалоге.

\section{СПИСОК ЛИТЕРАТУРЫ}

Брагина, Н.Г. Невежливость как ритуал (речевые формулы антикоммуникативного поведения) / Н.Г. Брагина // Ритуал в языке и коммуникации.-Москва: Знак; РГГУ, 2013.-С. 45-55.

Брагина, Н. Г.Педагогическая» агрессия в русской бытовой коммуникации / Н. Г. Брагина, И. А. Шаронов // Russian Journal of Linguistics.- 2019.- Vol. 23.- No. 4.C. 975-994.

Земская, Е. А. Категория вежливости в контексте речевых воздействий / Е. А. Земская // Логический анализ языка. Язык речевых действий. / Отв. ред. Н. Д. Арутюнова, Н. К. Рябцева.- Москва: Наука, 1994.- С. 130-137.

Иссерс, О.С. Коммуникативные стратегии и тактики русской речи: Изд. Стереотип. / О. С. Иссерс.-Москва, URSS, 2021.-308 с.

Кустова, Г.И. Косвенный речевой акт вопроса как средство речевой агрессии и негативной оценки в русской разговорной речи / Г.И. Кустова // Вопросы культуры речи / Отв. ред. А. Д. Шмелев.-Вып. 10.-Москва: АСТ, 2011.C. 229-235.

Николаева, Т. М. О принципе «некооперации» и/или о категориях социолингвистического воздействия / Т. М. Николаева // Логический анализ языка. Противоречивость и аномальность текста / Отв. ред. Н. Д. Арутюнова.Москва: Наука, 1990.- С. 225-235. 
Розина, Р.И. Анатомия хамства / Р.И. Розина // Вежливость и антивежливость в языке и коммуникации / Сост. и отв. ред. И. А. Шаронов.Москва: Росспэн, 2018.- С. 225-233.

Фишер, Р. Путь к согласию / Р. Фишер, У. Юри // Язык и моделирование социального взаимодействия.- Москва: Прогресс, 1987.-С. 173-207.

Шаронов, И. А. О допустимой резкости в русских стратегиях ведения диалога / И. А. Шаронов // Фразеология в контексте культуры. Российская академия наук, Институт языкознания, проблемная группа «Общая фразеология»; отв. редактор В. Н. Телия.- Москва: Языки рус. культуры: Кошелев, 1999.- С. 58-62.

Шаронов, И. А. Дискурсивные слова и коммуникативы / И. А. Шаронов // Компьютерная лингвистика и интеллектуальные технологии. По материалам ежегодной Международной конференции «Диалог».- Москва: Изд-во РГГУ, 2016.- С. 605-615.

Шатуновский, И. Б. Речевые действия и действия мысли в русском языке / И. Б. Шатуновский.- Москва: Языки славянской культуры, 2016.-480 с.

Шпильная, Н.Н. Стратегии и тактики коммуникативного поведения языковой личности в обыденной политической коммуникации/ Н. Н. Шпильная // Политическая лингвистика.-2017.--№ 5 (65).-С. 222-231.

Locher, Miriam. Interpersonal pragmatics and its link to (im)politeness research / M. Locher // Journal of pragmatics. - 2015. - No 86.- Pp. 5-10.

Malinowski, B. The problem of meaning in primitive languages / B. Malinowski // C. K. Ogden and J. A. Richards, "The meaning of meaning", New York; London, 9-th edition, 1953.- Pp. 296-336.

Yokoyama, Olga. Responding with a question in Colloquial Russian // Yokoyama, O. (ed.) Harvard Studies in Slavic Linguistics, vol. I, 175-194. Harvard University Slavic Linguistics Colloquium: Cambridge, MA, 1990.

\section{REFERENCES:}

Bragina,N. G. Nevezhlivost'kakritual(rechevye formuly antikommunikativnogo povedenija) / N. G. Bragina // Ritual v jazyke i kommunikacii.- Moskva: Znak; RGGU, 2013.- S. 45-55.

Bragina, N. G. Pedagogicheskaja» agressija v russkoj bytovoj kommunikacii / N. G. Bragina, I. A. Sharonov // Russian Journal of Linguistics.- 2019.- Vol. 23.No. 4.- S. 975-994.

Fisher, R. Put'k soglasiju / R. Fisher, U. Juri // Jazyk i modelirovanie social'nogo vzaimodejstvija. - Moskva: Progress, 1987.- S. 173-207.

Issers, O. S. Kommunikativnye strategii i taktiki russkoj rechi / O. S. Issers.Izd. stereotip.- Moskva, URSS, 2021.- 308 s.

Kustova, G. I. Kosvennyj rechevoj akt voprosa kak sredstvo rechevoj agressii i negativnoj ocenki v russkoj razgovornoj rechi / G. I. Kustova // Voprosy kul'tury rechi / Otv. red. A. D. Shmelev.- Vyp. 10.- Moskva: AST, 2011.- S. 229-235. 
Nikolaeva,T.M. O principe «nekooperacii» i/ili o kategorijah sociolingvisticheskogo vozdejstvija / T. M. Nikolaeva // Logicheskij analiz jazyka. Protivorechivost' i anomal'nost' teksta / Otv. red. N. D. Arutjunova.- Moskva: Nauka, 1990.- S. 225-235.

Rozina, R. I. Anatomija hamstva / R. I. Rozina // Vezhlivost' i antivezhlivost' v jazyke i kommunikacii / Sost. i otv. red. I. A. Sharonov.- Moskva: Rosspjen, 2018.S. 225-233.

Sharonov, I. A. O dopustimoj rezkosti v russkih strategijah vedenija dialoga / I. A. Sharonov // Frazeologija v kontekste kul'tury. Rossijskaja akademija nauk, Institut jazykoznanija, problemnaja gruppa «Obshhaja frazeologija»; otv. redaktor V. N. Telija.Moskva: Jazyki rus. kul'tury: Koshelev, 1999.- S. 58-62.

Sharonov, I.A. Diskursivnye slova i kommunikativy / I.A. Sharonov // Komp'juternaja lingvistika i intellektual'nye tehnologii. Po materialam ezhegodnoj Mezhdunarodnoj konferencii «Dialog».- Moskva: Izd-vo RGGU, 2016.- S. 605-615.

Shatunovskij, I. B. Rechevye dejstvija i dejstvija mysli v russkom jazyke / I. B. Shatunovskij.- Moskva: Jazyki slavjanskoj kul’tury, 2016.-480 s.

Shpil'naja, N. N. Strategii i taktiki kommunikativnogo povedenija jazykovoj lichnosti v obydennoj politicheskoj kommunikacii / N. N. Shpil'naja // Politicheskaja lingvistika.-2017.- № 5 (65).- S. 222-231.

Zemskaja, E.A. Kategorija vezhlivosti v kontekste rechevyh vozdejstvij / E. A. Zemskaja // Logicheskij analiz jazyka. Jazyk rechevyh dejstvij. / Otv. red. N. D. Arutjunova, N. K. Rjabceva.- Moskva: Nauka, 1994.- S. 130-137.

Locher, Miriam. Interpersonal pragmatics and its link to (im)politeness research / M. Locher // Journal of pragmatics. - 2015.- No 86. - Pp. 5-10.

Malinowski, B. The problem of meaning in primitive languages / B. Malinowski// C. K. Ogden and J.A. Richards, "The meaning of meaning”, New York; London, 9-th edition, 1953.- Pp. 296-336.

Yokoyama, Olga. Responding with a question in Colloquial Russian // Yokoyama, O. (ed.) Harvard Studies in Slavic Linguistics, vol. I, 175-194. Harvard University Slavic Linguistics Colloquium: Cambridge, MA, 1990. 